\title{
LIFESTYLE MEDICINE: WORKING TOGETHER TO REVERSE THE CHRONIC DISEASE EPIDEMIC IN LATIN AMERICA
}

\author{
Jhony A. De La Cruz-Vargas', Wayne Dysinger², Stephan Herzog ${ }^{3}$, Fabio dos Santos ${ }^{4}$, \\ Henry Villegas ${ }^{5}$, Margarete Ezinwa ${ }^{6}$
}

"Lifestyle medicine: a new medical discipline, from evidence to clinical practice"

\section{INTRODUCTION}

"Lifestyle Medicine" is revolutionizing health systems worldwide. This new field of medicine aims to reduce health costs, prevent diseases, and optimize therapeutic responses. In result, there is overall better quality of life for people. This new medical discipline includes everything related to lifestyles and the environment which has a strong evidence base, such as a healthy plant-based diets, exercise, stress management, cessation of tobacco and alcohol, adequate rest, healthy social relationships, emotional and spiritual health among others. Lifestyle Medicine modalities are used for preventing, and treating prevalent chronic diseases ${ }^{1,2}$.

For many years, it has been known that there is a direct connection between chronic diseases and the lifestyles people choose. We now know that $80 \%$ of health expenditures are due to the management of chronic diseases. The good news is that close to $80 \%$ of chronic diseases are treatable and often reversible with lifestyle changes. The Latin American Association of Lifestyle Medicine along with the leading international organizations in Lifestyle Medicine are "working to deal with the causes ", that is, the true roots of diseases ${ }^{3}$.

An innovative and high-impact concept in terms of public health is the "Reversal of Chronic Diseases with Lifestyle Medicine", an inverse process to the pathophysiology of chronic diseases, with increasing scientific evidence available in recent years ${ }^{4-5}$.

\section{WORLD HEALTH AND DISEASE STATISTICS: ${ }^{6-8}$}

Dr. Margaret Chan, Director-General of $\mathrm{WHO}^{6}$ stated that there are major challenges for the next decades in global health policies and programs. The globalized marketing of unhealthy products opened the door to increased chronic conditions in relation to lifestyle. Non-communicable diseases have surpassed infectious diseases as the leading cause of worldwide mortality. This is a unique moment in history, where economic progress, better living conditions, and greater purchasing power are actually increasing disease rather than reducing it. Social media platforms have become influential outlets, but rarely communicate accuracy in content. The growth of frontal groups and lobbyists promoting unhealthy products have created arguments that still overwhelm public knowledge and challenge evidence credibility. The Oxford Dictionary of the English Language chose "posttruth" as its word of the year for 2016. In a post-fact world, opinions that appeal to personal emotions and beliefs are, unfortunately, more influential than objective facts based on evidence.

\footnotetext{
President, Latin American Lifestyle Medicine Association (LALMA).

${ }^{2}$ Board Chair, American Board Lifestyle Medicine (ABLM).

${ }^{3}$ Executive Director, International Board of Lifestyle Medicine (IBLM).

${ }^{4}$ President, Brazillian Lifestyle Medicine Association (ABRASFEV).

${ }^{5}$ President, Costa Rica Lifestyle Medicine Society.

Executive Director, Lifestyle Medicine Global Alliance (LMGA).
}

Citar como: Jhony A. De La Cruz-Vargas, Wayne Dysinger, Stephan Herzog, Fabio dos Santos, Henry Villegas, Margarete Ezinwa. Lifestyle Medicine: working together to reverse the chronic disease epidemic in Latin America. [Editorial]. Rev. Fac. Med. Hum. 2017;17(1):10-12. DOI 10.25176/RFMH.v17.n1.742 


\section{What is the influence of Lifestyle in major chronic} diseases??

- $82 \%$ for heart disease

- $70 \%$ for Stroke

- $71 \%$ for Cancer

- 91 for Diabetes

- $99 \%$ for Obesity

An example of some of the statistical data: the number of adults living with diabetes has quadrupled since 1980 to date. This is related to overweith and obesity. It is estimated that approximately 422 million adults worldwide have type 2 diabetes. Globally, deaths related to diabetes amount to 1.5 million annually.

1.13 billion people around the world have high blood pressure. This number has nearly doubled since 1975. High blood pressure is a risk factor for cardiovascular diseases such as myocardial infarction, strokes, etc. Tobacco use remains one of the biggest defects in public health. One person dies every 6 seconds from a tobacco-related illness, accumulating to 6 million deaths per year. It is believed that by 2030 , tobacco will cause up to 8 million deaths per year. $80 \%$ of these tobaccorelated casualties will occur in developing countries.

Of the 57 million worldwide casualties in 2012, 63\% of those deaths were caused by preventable diseases: cardiovascular diseases, diabetes, cancer, and chronic respiratory diseases. Many of these deaths could have been avoided by multiple forms of prevention, such as avoiding physical inactivity and unhealthy diets. 2.8 million people die each year from cardiovascular disease and cancer, due to overweith and obesity. Approximately 3.2 million people die each year from physical inactivity. People with insufficient physical activity have a $20-30 \%$ higher risk of multiple-cause related deaths.

According to the United Nations Food and Agriculture Organization (FAO) and the Pan American Health Organization (PAHO), obesity rates have increased throughout Latin America and the Caribbean, with a greater impact on women and an upward trend in boys and girls. In the FAO and PAHO report, "The Panorama of Food and Nutrition Security in Latin America and the Caribbean", about 58\% of the inhabitants of the region are overweight (360 million people). Panorama points out that in Latin America and the Caribbean, 7.2\% of children under 5 are overweight. There is a total of 3.9 million children facing obesity. 2.5 million of these live in South America, 1.1 million in Central America and 200, 000 in the Caribbean. Current data in Peru show obesity rates of $40 \%$ to $60 \%$ in the population.
Diet was supposed to become the number 1 risk factor in 2020 but it happened faster than expected. The world is really eating in an unhealthy manner. We are eating, but not nurturing. In the "State of US health, 1990-2010: burden of diseases, injuries, and risk factors" document, the leading risk factors related to disability-adjusted life-years (DALYs) were: dietary risks, tobacco smoking, high body mass index, high blood pressure, high fasting plasma glucose, physical inactivity, and alcohol use ${ }^{8}$.

A negative factor in the current health model is that management and administration of diseases is encouraged (diagnostic-therapeutic model). According to an article in the Annals of Family Medicine, there is little evidence indicating the effectiveness of "disease management" in limiting health care costs. What should we do? Lifestyle Medicine shows us that great changes need to be made. We must transition from a "Disease Management" approach to a "Preventing, Stopping, and Reversing Diseases" approach. The road will not be easy as the opposing sides deem persistent. But as with tobacco, the truth speaks for itself.

\section{HISTORY OF THE LIFESTYLE MEDICINE MOVEMENT}

In 2004, John Kelly Jr., MD, MPH, a faculty member at Loma Linda University, started the American College of Lifestyle Medicine (ACLM). In 2007, Dr. Edward Philips MD, a faculty at the Harvard University School of Medicine created the Institute of Lifestyle Medicine (ILM). Conferences and publications followed, giving rise to the worldwide Lifestyle Medicine movement. Worldwide organizations followed: the Australian Lifestyle Medicine Association (ALMA), since changed to the Australasian Society for Lifestyle Medicine (ASLM); the European Society of Lifestyle Medicine (ESLM), since changed to the European Lifestyle Medicine Organization (ELMO); and the Asian Society for Lifestyle Medicine (ASLM).

In 2014, the foundation for the Latin American Lifestyle Medicine Association (LALMA) was established, leading to the first International Breast Cancer Congress which took place in association with multiple worldwide organizations in Lima, Peru in 2015. In Brazil emerged what is known as The Brazilian Association of Lifestyle Medicine (ABRASFEV), and in Costa Rica: the Lifestyle Medicine Costa Rica Society. More Lifestyle Medicine organizations are establishing in other countries of South America, Central America, and the Caribbean. 
LALMA currently works closely to develop the Lifestyle Medicine movement throughout Central and South American, and is connected to the Lifestyle Medicine Global Alliance (LMGA), the organization connecting the various worldwide Lifestyle Medicine organizations. LMGA is developing academic activities, scientific events, educational and research programs, as well as social awareness and collaborations with health authorities and universities around the world. LALMA is responsible for these activities as well as the certification process in the countries of Latin America.

\section{THE FUTURE OF LIFESTYLE MEDICINE}

What is the future of chronic diseases and lifestyle medicine? We believe there are three key elements in tackling current challenges:

\section{Education}

While in the past physicians may have had 4 hours of nutritional education during a 6-year medical education, more and more medical schools and hospital clinical courses are beginning to teach lifestyle medicine science. They are sensitizing community medical care with the ideas that food and physical activity are vital in the treatment of chronic diseases. Organizations such as the American College of Lifestyle Medicine (ACLM), the Latin American Lifestyle Medicine Association (LALMA), the European Lifestyle Medicine Organization (ELMO), the Asian Society of Lifestyle Medicine (ASLM) and the vanguard, are all joining the Global Alliance of Lifestyle Medicine, where a key goal is improved Lifestyle Medicine education. When the medical community can learn and practice "health care" instead of "disease care," then they will begin to embrace what is Lifestyle Medicine.

\section{Certification}

The American Board of Lifestyle Medicine, along with the International Board of Lifestyle Medicine with the support of the above organizations, is preparing a global certification and examination framework for physicians and other practitioners of Lifestyle Medicine. The first examination will be held in Tucson, Arizona, United States in October 2017. This will be followed by a second exam in Sydney, Australia in November 2017, and a third in Manila, Philippines in March 2018. This will establish a cadre of medical clinicians accredited in evidence based Lifestyle Medicine, and differentiate them from those claiming to practice Lifestyle Medicine in ways that are not scientifically based. This certification process will open a global platform in which credibility, problematic administrative resolutions, and financial redemption issues can be addressed and met.

\section{Economics}

In order for Lifestyle Medicine to become the first line of defense in treatment of chronic diseases, it must economically suit all parties: patients, doctors, health grants, national and state governments, and health systems as a whole. When patients realize that it is not only their genes, but also their lifestyles, that led to their illness, hope is restored. This is because those same lifestyles can change for the better. Changes are made, health is restored, and costs are minimized. When doctors can get equal pay for prescribing Lifestyle Medicine based regimens, including plant based nutrition and daily exercise programs, instead of prescribing pills and various medications in isolation, then there will be a greater understanding for the need for this change. When those who pay for health care (individuals, corporations, governments) realize that chronic illnesses can be reversed and in turn costs reduced, then Lifestyle Medicine will be positioned to thrive.

\section{REFERENCES}

1. Ramón Mora Ripoll. Lifestyle medicine: The importance of considering all the causes of disease . Rev Psiquiatr Salud Ment (Barc.). 2012;5(1):48-52.

2. Robert F Kushner and Jeffrey Machanick. Lifestyle Medicine-An Emerging New Discipline. US Endocrinology, 2015;11(1): 36-40. DOI: 10.17925/ USE.2015.11.01.36

3. American College of Preventive Medicine. Lifestyle medicine- Evidence Review 2009. Available at: http://www.acpm.org/LifestyleMedicineLiteratureReview. pdf.

4. M. Sagner, D. Katz, G. Egger, L. Lianov, K.-H. Schulz, M. Braman, B. Behbod, E. Phillips, W. Dysinger, D. Ornish, Lifestyle medicine potential for reversing a world of chronic disease epidemics: from cell to community. Int J Clin Pract, November 2014, 68, 11, 1289-1292. doi: 10.1111/ijcp.12509

5. Esselstyn, C. \& Golubic, M. The nutritional reversal of cardiovascular disease,
Fact or Fiction? Three case reports. Exper. Clin. Cardiol. 20, 1901-1908 (2014).

6. World Health Organization: Grand challenges for the next decade in global health policy and programmes. Available at: http://www.who.int/dg/ speeches/2017/address-university-washington/en/

7. Arena R, Guazzi M, Lianov L, Whitsel L, Berra K, Lavie CJ, Kaminsky L, et al. Healthy Lifestyle Interventions to Combat Noncommunicable Diseased - A Novel Nonhierarchical Connectivity Model for Key Stakeholders: A Policy Statement From the American Heart Association, European Society of Cardiology, European Association for Cardiovascular Prevention and Rehabilitation, and American College of Preventive Medicine. Mayo Clinic Proceedings 2015; DOI: 10.1016/j.mayocp.2015.05.001

8. US Burden of Disease Collaborators. The State of US Health, 1990-2010Burden of Diseases, Injuries, and Risk Factors. JAMA. 2013;310(6):591-606. doi:10.1001/jama.2013.13805. 